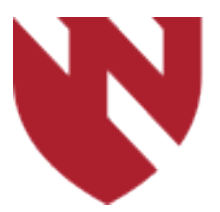

December 2019

\title{
Nonspecific Interstitial Pneumonia Development after Fire Extinguisher Dust Inhalation
}

\author{
Maureen C. McElligott \\ University of Nebraska Medical Center \\ Daniel Hershberger \\ University of Nebraska Medical Center
}

Tell us how you used this information in this short survey.

Follow this and additional works at: https://digitalcommons.unmc.edu/gmerj

Part of the Higher Education Commons, and the Medicine and Health Sciences Commons

\section{Recommended Citation}

McElligott, M. C., , Hershberger, D. Nonspecific Interstitial Pneumonia Development after Fire Extinguisher Dust Inhalation. Graduate Medical Education Research Journal. 2019 Dec 13; 1(1).

https://digitalcommons.unmc.edu/gmerj/vol1/iss1/61

This Conference Proceeding is brought to you for free and open access by DigitalCommons@UNMC. It has been accepted for inclusion in Graduate Medical Education Research Journal by an authorized editor of DigitalCommons@UNMC.For more information, please contact digitalcommons@unmc.edu. 
Nonspecific Interstitial Pneumonia Development after Fire Extinguisher Dust Inhalation

\section{Creative Commons License}

\section{c) (1)@ $\Theta$}

This work is licensed under a Creative Commons Attribution-Noncommercial-No Derivative Works 4.0 License. 
collected. Descriptive data and trends were analyzed using SPSS software.

Results: 233 female participants provided the requested information. Over $20 \%$ of the participants endorsed significant agriculture exposure defined as greater than or equal to 2 years exposure that occurred predominately during youth and young adulthood. Exposure included both livestock and crops, with the most common exposures being corn, soybeans, and beef cattle. In addition, $55 \%$ reported significant second-hand smoke exposure during youth. More than half (53\%) reported at least one respiratory disease, which included allergic rhinoconjuntivitis $(45 \%)$, sinusitis $(10 \%)$, asthma (6\%), chronic obstructive airway disease $(2 \%)$, and pneumonia (14\%).
Conclusions: Agriculture and second-hand smoke exposures were common early life exposures in post-menopausal women of the Heartland Osteoporosis cohort that could impact development of respiratory diseases. Future analysis will investigate how environmental exposures and respiratory diseases influence post-menopausal health and bone health

https://doi.org/10.32873/unmc.dc.gmerj.1.1.059

\section{Assessment of Treatment Response using the Multi-Biomarker Disease Activity Score in Rheumatoid Arthritis Patients Initiating Methotrexate}

Tate Johnson, Bryant England, Harlan Sayles, Geoffrey Thiele, Ted Mikuls, James O'Dell

Mentor: Bryant England

Program: Internal Medicine

Background/Purpose: The Multi-Biomarker Disease Activity (MBDA) score was developed to provide an objective measure of rheumatoid arthritis (RA) disease activity. The ability of the MBDA to predict treatment response may vary among disease-modifying agents, and has not been evaluated in patients initiating methotrexate (MTX), a cornerstone therapy in RA.

Methods: We conducted a secondary analysis of an open-label study of RA patients initiating MTX. The association of MBDA scores at baseline $(\mathrm{N}=130)$ and week 16 $(\mathrm{N}=95)$ with treatment response was assessed using multivariable regression models. Convergent validity and responsiveness were determined by calculating correlations of the MBDA with disease activity measures and through the calculation of standardized response means (SRM).

Results: Patients achieving an ACR50 response demonstrated greater reductions in MBDA than those failing to achieve an ACR50 response $(\mathrm{p}=0.01)$. However, baseline MBDA scores (OR 1.01, 95\% CI 0.99, 1.04) and categories (moderate: OR 1.55, 95\% CI 0.45-14.20; high: OR 2.55, 95\% CI 0.5012.98 ) were not predictive of response. Higher baseline MBDA scores were associated with greater improvement in DAS28-ESR $(\mathrm{p}=0.01)$, as were baseline DAS28-ESR values $(\mathrm{p}<0.001)$. The MBDA demonstrated moderate correlations with DAS28-ESR and ESR, but weaker correlations with the HAQ and PtGA. Treatment responsiveness was greater for DAS28-ESR (SRM -1.32) than MBDA (SRM -0.65).

Conclusions: Baseline MBDA was associated with greater reductions in DAS28-ESR but was not a robust predictor of ACR50 response. Although demonstrating moderate convergent validity with standard disease activity assessments, the MBDA yielded lower responsiveness than the DAS28-ESR in the context of MTX treatment.

https://doi.org/10.32873/unmc.dc.gmerj.1.1.060

\section{Nonspecific Interstitial Pneumonia Development after Fire Extinguisher Dust Inhalation \\ Maureen McElligott and Daniel Hershberger}

Mentor: Daniel Hershberger

Program: Internal Medicine

Introduction: Nonspecific interstitial pneumonia (NSIP) is a form of chronic inflammatory idiopathic interstitial pneumonia. It typically presents with months of dyspnea. NSIP is frequently associated with connective tissue disease, HIV, and druginduced lung disease.

Case Presentation: A middle-aged patient, non-smoker with hypertension and OSA on CPAP presented with six months of exertional dyspnea and right-sided chest pain. The patient developed a new exertional 10 LPM supplemental oxygen requirement after significant smoke and fire extinguisher dust inhalation. The patient denied a family history of lung disease or connective tissue disease, had faint inspiratory crackles, and no leg edema.

ANA, RF, ANCA, IgE, CK, aldolase, anti$\mathrm{CCP}, \mathrm{HIV}$, and hypersensitivity pneumonitis panel were unremarkable. Chest CT revealed diffuse ground glass sparing the costophrenic angles without traction bronchiectasis and honeycombing. Pulmonary function testing revealed FEV1/FVC of $82 \%$, TLC was $56 \%$ predicted, and DLCO was $63 \%$ predicted. EF was normal and pulmonary artery systolic pressure was $45-50 \mathrm{mmHg}$. Right lower lobe wedge biopsy demonstrated alveolar wall thickening with focal lymphocytic inflammation in a fairly uniform distribution without honeycombing, consistent with NSIP. The patient underwent pulmonary rehabilitation and was started on Prednisone and transitioned to Azathioprine resulting in improvement of his dyspnea.

Discussion: Diagnosis of NSIP is dependent on multidisciplinary interactions among pulmonology, radiology, and pathology to differentiate it from other interstitial lung diseases and guide treatment. The patient developed hypoxic dyspnea within months of fire extinguisher dust exposure and lacked other risk factors for development of NSIP. Fire extinguisher exposure is typically associated with desquamative interstitial pneumonia, and per our literature review, there are no reported cases of fire extinguisher exposure related to NSIP, making this case unique.

Conclusion: It is probable that exposure to smoke and fire extinguisher dust inhalation triggered the development of NSIP.

https://doi.org/10.32873/unmc.dc.gmerj.1.1.061 